\title{
HALK BILIMİ ARAŞTIRMALARINDA YAZILI KAYNAK OLARAK SÜLEYMAN-NÂME
}

\begin{abstract}
Özet
Kültürün korunması ve sistemli bir şekilde gelecek kuşaklara aktarılması fikrinin henüz bilimsel temele oturmadığı dönemlerde ortaya konulan yazılı eserlerin halk bilimi çalışmalarına kaynaklık ettiği bilinmektedir. Türk edebiyatının yazıl1/kültürel belleği olarak adlandırılabilicek bu eserler, yazıldığı dönemin sosyo-kültürel hayatına dair bilgiler de içermektedir. Bu bilgiler sözlü bellekteki kültürel malzemenin yazıya geçirilmesi, o dönemin kültürel hayatının öğrenilmesi ve aktarılması noktasında değerlidir. Özellikleri bakımından kültürün çok yönlü yapısı tarih boyunca çeşitli edebi eserlerde farklı alanlarda kendine yer bulmasına yol açmıştır. Tarihte yaşamış toplumların yaşadıkları dönemdeki kültürel değerlerine dair verilerin/izlerin ilgili dönemde yaşamış tarihçiler, edebiyatçılar ve meraklılarınca yazılan eserlerde yer aldığı bilinmektedir. Bu yer alma biçimi bugün kültürün gelecek kuşaklara bir "insanlık mirası” olarak aktarılması fikrinden uzak, çoğu farkında olmaksızın gerçekleşmiştir. Ancak bu farkında olmama durumu bile, eserin bize 1şık tuttuğu dönemin, sosyokültürel hayatı ile ilgili önemli bilgiler vermektedir. Firdevsî-i Rûmî'nin Süleyman-nâme adlı eserinin; içinde barındırdığı halk kültürüne ait unsurlarla dönemin yaşayış, adet, gelenek ve göreneklerini yansıtması bakımından çok önemli bir yeri vardır. Bu çalışmada Firdevsî-i Rûmî’nin Süleyman-nâme adlı eserinin 67 ve 68. ciltlerinde bulunan halk kültürüne ait unsurlar derlenmiş ve değerlendirilmiştir.
\end{abstract}

Anahtar Kelimeler: Firdevsî-i Rûmî, Süleyman-nâme, Halk Bilimi, Yazılı Bellek, Kültür.

\section{SULEYMANNÂME AS WRITTEN SOURCE IN FOLKLORE RESEARCH}

\begin{abstract}
Preserving culture and the idea of transferring, yet written works produced in the period in which the scientific basis is the source for folklore studies. These works, known as the cultural memory of Turkish literature, The period written contains information about the socio-cultural life. This information will be recorded in writing for cultural material in verbal memory and to learn the cultural life of that period and is valued the transfer points. The multifaceted nature of the cul- ture in terms of its features has led to its place in various fields in various literary works throughout history. It is known that many forms of life, in which many societies have no cultural continuity or are erased from the history of the history, having their cultural values involved in written works by historians, writers or enthusiasts who lived at that time. This way of taking place today has been realized without much awareness, far from the idea of the culture being passed on to future generations as a "human inheritance". But even this lack of awareness gives important information about the socio-cultural life, when the work sheds light on us. The data on public life encountered in these books used to be written information sources, without greatly being aware it was included into the work. In this regard it is important to identify the cultural elements that are meet in the works and it is important to add to the literature. In this sense, the work of Firdevsi-i Rumi's called Solomon-name 67 or 68 cultural elements encountered in the text translated into modern Turkish folklore are evaluated under the skin cadres.
\end{abstract}

Keywords: Firdevsî-i Rûmî, Süleyman-nâme, Folklore, Written Memory, Culture. 


\section{GİRIŞ}

Yazı ve matbaa kavramlarının varlığının bile bilinmediği, iletişimin yalnız konuşma dilinden oluştuğu kültürleri Ong, "birincil sözlü kültür" olarak niteler. Buna karş1lık günümüz ileri teknolojisiyle hayatımıza giren telefon, televizyon ve diğer elektronik araçlar "sözlü" nitelikleri, üretimi ve işlevi yazı ve metinden çıkarıp konuşma diline dönüştürdüğü için “ikincil sözlü kültür’ü oluşturur. Bugün hemen her kültürde bir yazı kavramı ve bu kavrama dayanan bir yazı deneyimi bulunduğu için gerçek anlamda birincil sözlü kültür pek kalmamıştır. Fakat ileri teknolojiden yararlanan pek çok kültürde ve altkültürde, hâlâ birincil sözlü kültürden kalma düşünce biçimlerine rastlamak mümkündür (Ong, 2012: 23-24).

Halk edebiyatı ürünlerinin beslendiği kaynağı, üretim ve aktarım biçimi gibi temel özellikleri itibariyle sözlü kültür ortamının malıdır ve sözlü anlatımla gelecek kuşaklara taşınır. İlhan Başgöz’ün ifadesiyle, bu sözlü anlatım ise bir sosyal olaydır (1992: 1). Bu ürünler, sözlü kültür ortamında yaratılmış ve kuşaktan kuşağa sözlü iletişim vasıtasıyla aktarılmıştır. Yazılı kültürün gelişmesiyle hem bağımsız bir şekilde yazıya geçirilmeye hem de parça ya da bölümler halinde çeşitli yazılı eserlere girmeye başlamıştır. Bu vesileyle araştırıcılar, bugün bilinen herhangi bir ürünün bundan önceki yüzyıllardaki şekillerini bu yazılı kaynaklar vasıtasıyla takip edebilme imkânını bulabilmişlerdir. Hatta sözlü kültür ortamında günümüze ulaşmayan bazı halk edebiyatı ürünlerinin geçmişteki varlığından ancak yazılı eserler vasıtasıyla haberdar olabilmekteyiz (Aça, 2010: 93).

Sözlü anlatılar bir müddet sonra yazının icadı, teknolojik gelişmeler vb. nedenlerle yazılı ifadelerde de yer bulmaktadır. "Yazı sahibi toplumlardaki sözlü iletişim, yazısı olmayan toplumlardaki sözlü iletişim ile aynı değildir. İkincisinde, sözlü gelenek, kültürel aktarımın bütün yükünü taşımak zorundadır. Okur-yazar toplumlarda ise, sözlü gelenek, kalıplaşmış fiil biçimlerinden oluşan yazınsal eylem bütünlüğünün bir parçası durumdadır.” (Goody, 2009:128). Sözlü kültür ürünleri, yazı ve teknolojik gelişmeler gibi nedenlerden dolayı ikinci plana düşmüş gibi görünseler de her zaman için geçerliliklerini sürdürebilmektedirler. "Her ne kadar yazının icadı ve yaygınlaşması, içinde bulunduğumuz elektronik ortamla iletişim ağlarının zenginlik kazanması sözlü bellek ve sözlü kültür açısından olumsuzluk olarak düşünülse de sözlü bellek insanoğlu için başvuracağı en yakın ve en doğal kaynak olarak günümüzde de varlığını sürdürmektedir.” (Fidan, 2011: 140'den Aktaran Özcan ve Gönenç, 2015: 723)

Türk folkloru ve halk edebiyatı yazılı, sözlü ve elektronik olmak üzere üç önemli kaynaktan beslenmektedir. Bu kaynaklardan ilki üzerinde yerli ve yabancı araştırıcılar zaman zaman çalışmışsa da bütün yazılı kaynakların incelendiğini söylemek mümkün değildir (Alptekin, 2014: 52). 
Bir ulusun, bir halkın, bir yörenin ya da bir etnik grubun yaşamıyla ilgili çeşitli yanlarını, âdetlerini, geleneklerini, göreneklerini, inanmalarını, becerilerini vb. yazıya geçirmiş kimselerin yazma ya da basılı yapıtları, yazıya dökülmüş anıları, gezi notları, gözlemleri, izlenimleri yazılı kaynakları oluşturur. Bu türden yazarı bilinen belirli yapıtların yanı sıra, yazarı, yaratıcısı ve yazılış tarihi bilinmeyen, "anonim” denilen, yaratılmasında ve yaşatılmasındaki tarihsel süreç içinde birçok kişinin katkısı olan kaynaklara da sözlü kaynaklar denmektedir (Örnek, 2000: 29-30). Bu türden yazarı, yaratıcısı ve ortaya çıkış tarihleri kesinlikle bilinmeyen ürünlere karşılık bir de "bibliyografik" künyeleri bilinen yapıtlar vardır. Bunlar bir ulusun, bir halkın ya da bir yörenin geçmiş dönemlerine ilişkin yaşamları, kültürleri hakkında değerli bilgiler içermektedir. Köklü bir ulusun, bir halkın geçmişinin ortak değerlerini, inançlarını aydınlatan; bugün bile işlerliğini, canlılığını, etkinliğini koruyan kimi kültürel öğelerin ve kurumların yapılarına ve köklerine 1ş1k tutan birçok bilgiyi, açıklamayı bu kaynak yapıtlarda bulmak; bugünle geçmiş arasında bağlantılar ağı kurmak; geçmişle bağ kurulan pekçok kültürel izli belirtiyi dar kalıplardan kurtarıp tarihsel uzantısına bağlamak bu kaynakların aracılığıyla olur (Örnek, 2000: 30). Orhun Yazıtları, Kutadgu Bilig, Divânü Lugat-itTürk, Dede Korkut Kitabı, İbn Batuta Seyahatnamesi, Babürnâme, Katip Çelebi’nin Yapıtları, Evliya Çelebi Seyahatnamesi, Süleyman-nâme gibi eserler bunlardan birkaçıdır.

Halk edebiyatı alanında çalışanlar, üzerinde bilimsel yöntemleri kullanarak inceleme ve değerlendirme yapacakları verileri sadece "sözlü kaynaklar"dan elde etmezler. Bu noktada yazılı kültürün gelişmeye başladığı dönemlerden itibaren kaleme alınan eserleri de dikkate alma, eğer içlerinde geçmiş dönemlere ait halk edebiyatı ürünleri günümüz bazı problemlerini çözmeye yardım edecek bilgileri barındırıyorlarsa, araştırma ve incelemelerine bu metinleri de dâhil etmek durumundadırlar (Aça, 2010: 98). Ancak, geçmiş dönemlerde yazılı kaynaklarda halk edebiyatı ürünlerine yer verenlerin çoğu, folklor çalışmalarının başlamasıyla ortaya çıkan bilimsel ilgiye benzer şekilde doğrudan halk edebiyatı ürünlerine dayalı eserler yazmayı amaçlamamışlardır. Çeşitli vesilelerle halk edebiyatı ürünlerine eserlerinde yer verenleri, bugünkü anlamda derleyiciler ya da sözlü kültür araştırıcıları olarak nitelendirmek mümkün değildir (Aça, 2010: 94). Ancak bu edebî metinler, oluşturuldukları döneme ait kültürel değerler ile sosyal, siyasal, tarihî, mitolojik, ekonomik unsurları içlerinde barındırırlar. Bunda da yazarın içinde yaşadığı toplumun kültürel değerlerini malzeme olarak kullanmasının büyük etkisi vardır (Özdemir, 2011: 3).

Avrupa'da olduğu gibi bizde de, halk biliminin ortaya çıkmasından önce "içeriğinde folklor öğelerini bulunduran" eserler yazılmıştır. Yazma basma nüshaları dolduran bu eserler, Türk folklorunun tarihi kaynaklarını meydana getirdiğinden ve birçok bakımdan bugünün folkloruna 1şık tutacağından dönem dönem düzenlenerek yayımlanmaktadır (Alangu, 1983: 130). 11. yüzyıldan 19. yüzyılın yarısına kadar süren, ondan sonra da etkileri duyulan ve "Divan edebiyatı" adıyla anılan büyük sanat 
akımı, üzerinde az çok durulduğu, kaynakları bir dereceye kadar yayımlandığı, sanat aşamaları açısından da değerlendirilip yargılandığ yeterince durulmamıştır (Alangu, 1983: 131).

İşte bu metinlerden biri de Firdevsî-i Rumî tarafından 15. yy’ın ikinci yarısında kaleme alınan Süleyman-nâme adlı eserdir. Süleyman-nâme 80 ciltten oluşan hacimli bir eserdir. Burada ele alınacak olan halk kültürü unsurları, bu eserin 67. ve 68. ciltlerinin Latin harflerine aktarılmasıyla ortaya çıkan metnin incelenmesi sonucu ortaya çıkarılmıştır.

Firdevsî-i Rûmî’nin eserlerinde , “sözlü gelenek” ve “yazılı gelenek” unsurlarının çokça bulunduğu görülmektedir. Şimdiye kadar genellikle edebiyat tarihi alanının konusu olarak incelenilen bu eserlerin halkın kültürüne bağlı olarak yaşayıp gelmesi, içerisinde bulunan unsurların, halkın hayat ve kültürünü yansıtan öğelerin folklor açısından yeniden ele alınıp değerlendirilmesi gerekmektedir (Alangu, 1983: 132). Çünkü bir yanıyla halk edebiyatı ve klasik Türk edebiyatı, Türk edebiyatının birbirleriyle ilişkili uzun soluklu edebî gelenekleridir (Sona, 2016: 77).

Süleyman-nâme'de halk bilimi unsurları çerçevesinde, halk kültürünün sözlü gelenek unsurlarının, eserin yazıldığı dönemde ne şekilde aktarıldığı tespit edilecek ve derlenilen bilgiler bu makalede ele alınacaktır. Bu çalışmada, Süleyman-nâme'de geçen yazılı ve sözlü kültür ürünleri olan halkın adet, gelenek ve göreneklerinin nasıl ve ne şekilde aktarıldığından bahsedilecektir. Ancak konuya geçmeden önce gerek eserlerle gerekse kültür ve yazılı ortamda kültür aktarımıyla ilgili bilgilere değinilecektir.

\section{KÜLTÜRÜN AKTARILMASI}

Bireylerin temel gereksinimleriyle birlikte, sosyal yaşamın sürekliliğini de sağlayan ve sosyal miras ve gelenekler sistemi olarak kültür, Edward Sapir'in tanımıyla, varlığımızın yapısını (ilişkilerini) belirleyen, sosyal bir süreçle öğrendiğimiz uygulama ve inançların, maddî ve manevî öğelerin birliğidir (1921, 4: 402, Güvenç, 1974: 101). Tylor'un tanımına göre ise kültür, bir toplumun üyesi olarak, insanoğlunun öğrendiği (kazandığı) bilgi, sanat, gelenek-görenek ve benzeri yetenek, beceri ve alışkanlıkların bir bütünüdür (1871: I, Güvenç, 1974: 102).

Özellikleri bakımından, içgüdüsel ve kalıtımsal olmayan, her bireyin doğduktan sonraki yaşantısı içinde kazandığı alışkanlıklar olan kültür (Güvenç, 1974); öğrenilirdir, süreklidir, toplumsaldır, ihtiyaçları karşılayıcıdır, doyum sağlayıcıdır, bütünleştiricidir ve değişir. Bu özellikleri bakımından kültürün çok yönlü yapısı tarih boyunca çeşitli edebi eserlerde farklı alanlarda kendine yer bulmasına yol açmıştır. Kültürün ya da diğer bir ifadeyle tarih sahnesinden silinmiş devamı olmayan birçok toplumun sahip olduğu yaşama biçimlerinin, kültürel değerlerinin o dönemde yaşamış tarihçiler, edebiyatçılar veya meraklılarınca yazılan eserlerde yer aldığı bilinmektedir. Bu yer alma biçimi 
bugün kültürün gelecek kuşaklara bir “insanlık mirası” olarak aktarılması fikrinden uzak, çoğu farkında olmaksızın gerçekleşmiştir. Ancak bu farkında olmama durumu bile, eserin bize 1şık tuttuğu dönemin, sosyo-kültürel hayatı ile ilgili önemli bilgiler vermektedir. Diğer taraftan insanlık sahip olduğu somut kültürel mirası korumaktaki bilinçlilik düzeyine ulaşmışken, bu refleksi somut olmayan kültürel mirasın aktarılması konusunda göstermemektedir. Oysa Tahir Alangu'nun Türkiye Folkloru El kitabında dile getirdiği gibi; çöküp dağılan her köylü evi, ölen her çalışma düzeni, unutulan her türkü, önlenemez ve ihya edilemez ölçüde halk hayatından bir parçayı ortadan silip yok etmektedir (1983: 82).

Geleneksel açıdan incelendiğinde kültür, bir toplumda kimi zaman örf ve adet, kimi zaman sanatsal ya da estetik bir bakış açısında karşımıza çıkabilir. Bu kültür tipi daha çok kolektif yani daha çok toplum tarafından benimsenir. Bu bağlamda geçmişten günümüze aktarılabilen bütün somut ve somut olmayan değerler, kolektif kültürün birer öğesidir ve miras özelliği taşımaktadır (Diker, 2016: 367). Kültürel miras kavramının "somut" olandan "somut olmayana” doğru geçirdiği evreler önemlidir. Yakın zamana kadar kültür turizmini tetikleyen unsurlar düşünülüğünde ilk olarak mimari, doğa güzellikleri ya da doğa olayları gibi gözle görülebilen elle dokunulabilen somut nesneler akla gelmiştir (Özünel, 2011: 257). Somut ve somut olmayan kültürel miras arasındaki bu eşitsiz yaklaşım Sercan Gülçayır'ın Somut Olmayan Kültürel Mirasın Korunması Sözleşmesi Üzerine Eleştirel Bir Bakış adlı makalesinde dile getirdiği gibi, somut ve somut olmayan kültürel miras arasındaki hiyerarşik konumlanmanın bir neticesidir (2011: 6). Somut olmayan kültürel mirasın korunması konusunda "ulaşımda at mı kullanılıyor elbette nalbantlar birer birer kaybolacak", "masal dinleyen mi var elbette masal anlatıcısı kalmayacak ”biçiminde işleyen mantığın bu “doğal bir Efes Antik Kenti, Sümela Manastırı, Topkapı Sarayı için “artık kullanılmıyorlar nasılsa, yerlerine modern mimari tekniklerle başka binalar yapalım" seslerinin yükselmesi bir yana bu yapıları titizlikle korumanın üzerine kafa yorulur (Gürçayır, 2011: 6-7).

Konumuza geri dönecek olursak edebi eserlerde karşımıza çıkan halk kültürü unsurları da somut olmayan kültürel mirasın bir parçasıdır ve gelecek kuşaklara aktarmak için, tespit edilmesi, değerlendirilmesi, literatüre kazandırılması, son noktada Metin Ekici'nin, halk bilim araştırmalarında üçüncü boyut olarak dile getirdiği, “temsil ve sunum”unun imkânlar dâhilinde gerçekleştirilmesi gerekmektedir. Aynadaki hayal, kendisine akseden eşyaya benzer. Edebiyat, bu manada kültürün aynadaki aksine benzetilebilir. Bu demektir ki, kültür sahasında ne varsa, onların hepsinin akislerini edebiyatta bulmak mümkündür (Kaplan, 2012: 11). Bu açıdan bakıldığında Süleyman-nâme'nin sözlü kültüre ait özelliklerin hacimli bir şekilde yazıya geçirildiği bir eser olması bakımından incelenmesi son derece önem arz etmektedir. Makalenin inceleme kısmında Süleyman-nâme'de yer alan halk kültürüne ait veriler örneklerle değerlendirilecektir. 


\section{FİRDEVSÎ-İ RÛMÎ VE SÜLEYMAN-NÂME}

II. Beyazıd adına yazdığı Süleyman-nâme adlı eseriyle tanınan Osmanlı müellifi Firdevsî-i Rûmî, İslam ansiklopedisindeki bilgilere göre, 1453 yılında Edincik’te (Aydıncık) doğdu. Hayatını Edincik, Bursa, Manisa ve civarında geçiren Firdevsî, bir süre de İstanbul' da yaşamıştır. Genç yaşlarında tarih, kısas, hendese ve ilm-i nücûm gibi konulara ilgi gösteren Firdevsî, bir taraftan da Simavlı Nakşi Şeyhi Abdullah-1 İlahi’ye intisap ederek tasavvufa yönelmiştir. Şairlik kabiliyetinden mahrum olan Firdevsî’nin, gerek çağdaşları gerekse sonraki tezkireciler tarafından şairliğinin yetersizliği belirtilmiştir. Ancak bununla beraber çeşitli alanlarda verdiği eserler bakımından da önemine vurgu yapılmıştır. Çok sayıda değişik konulardan telif ve tercüme olarak kırktan fazla eser bıraktığı söylenirse de bugün bunlardan ancak bir kısmı bilinmektedir (Köprülü, 1996: 128).

Eski Anadolu Türkçesi döneminde eserlerini veren Firdevsî-i Rûmî telif ve tercüme çok sayıda eser sahibi bir yazardır. Çok sayıda ve birçok türde eser ortaya koyan Firdevsî’nin kitaplarında; yaşadığı dönemle ilgili çeşitli bilgilerle beraber, insanlık tarihine ait dinî inançlar özellikle Doğu mitolojisi, peygamber kıssaları ve hayatın çeşitli yönlerine dair geniş malumat yer alır (Ahmed, 2014: 104-105).

Süleymân-nâme, Hz. Süleymân hakkında söylenilen bütün dinî, efsanevî hikâyelerin bir araya toplandığ1 ve Uzun Firdevsî’ye asıl ününü kazandıran en hacimli eseridir.

Cilt ve meclis sayılarında birçok farklı rivâyet olsa da günümüze 81 . ciltlik büyük bir külliyât kalmıştır. Bu eserin içinde felsefe, hendese, ilm-i nücûm ve hekimliğe dâir bilgiler bulunur. $\mathrm{Bu}$ bakımdan ansiklopedik bir eser mahiyeti de taşır. Eserin büyük bir kısmı mensurdur. Manzum bölümler başta ve sonda bulunurken, her hikâye bitiminde de konuya uygun olarak manzum metinler yer alır. Ancak manzum kısımlar eserin çok az bir bölümünü oluşturur (Erdem, 2005:1).

Firdevsî-i Rûmî, Süleymân-nâme muhtasârında Süleymân-nâme kitabının hikâyesini şöyle nakletmiştir: "Yıldırım Bâyezîd Han'a Mevlânâ Ahmedî gelip tevârihden eline geçen miktarı cem idüp, İskender-nâme sûretine getirüp güzel söz ve beyitlerle süslemiştir. Şöyle kim ol miktar sözde medh-i mukadder uygun değildir, 360 mücelled kitab yazmak onun gücünün sınırlarını aştı, bu kadar çok yazmaktan çekindi ve özet yoluna başvurdu ki esma-i hüsnâ adedince 99 cilde temam eyle denilmişti. Mevlânâ dahi 120 cilde ancak tamam idelüm deyüp başım gözüm üstüne dedi ancak yazamadı. Buna karşılık bu hakîr-i nâ-sevâb Firdevsî, taht-1 Kostantiniyye'de başlayıp altmış sekiz cildini temam eyledüm” (Biçer, 2005: 50).

Asuman Akay’ın “Firdevsî-i Rûmî’nin Süleyman-nâme-i Kebîr'indeki Deyimler” başlıklı makalesinde aktardığına göre; Süleymân-nâme-i Kebîr üç padişahın saltanat yıllarını içine alması 
yönünden çok önemli bir yerinin olmasının yanı sıra kaleme alındığı zamana kadar Anadolu'da kendi türünün kapsam ve içerik yönünden en hacimli eseridir. Süleymân-nâme içerdiği konular bakımından çok kapsamlı olup Süleyman Peygamber etrafında şekillenmiş olan kıssa ve rivayetleri ele almasının yanı sıra Doğu mitolojisi, diğer peygamberlerin kıssaları, tarih, hikmet, felsefe, ahlâk ve tıbba ait konuları da içerir. Eser manzum ve mensur karışık olarak sade bir şekilde yazılmış olup ses ve söz tekrarlarının anlatımda sağladığı ahenk itibariyle de Dede Korkut Hikâyeleri ile paralellik taşıdı̆̆ı noktasında dikkat çekmektedir (Akay, 2014: 105). Eserlerde yazarın, Tevrât, İncil, Zebûr ve Kur'ân-1 Kerîm'den yararlanmakla kalmayıp peygâmber kıssaları, târîh kitapları (bu konuda en büyük kaynağı Taberî’dir), fen ve gizli ilimlere sahip kaynaklar gibi birçok kaynaktan istifâde edip Süleymân-nâme gibi hacimli bir eseri ortaya koyduğu görülmektedir. Babür'ün de belirttiği gibi: "Süleymân-nâme"nin tüm ciltleri bulunup Latin harflerine aktarılmadıcça Firdevsî ve Süleymân-nâme hakkındaki bilgiler yetersiz ve çelişkili kalacaktır. Bu hacimli eser ilim âlemine bir an önce kazandırılmalıdır (Babür, 2013:4)

\section{SÜLEYMANNÂME'DE GÖRÜLEN HALK BİLIMİ UNSURLARI}

\section{Hz. Süleymân ve Çevresindekiler}

Hz. Süleymân ve çevresindekiler başlığı altında, Hz. Süleymân'ın tahtında devlet işlerini gören yönettiği ülkelerin görevlileri, tahtgahındaki vazifeli bürokratlar özel işlerini gören aşçıbaşı vs. gibi kişiler tespit edilmeye çalışılmıştır. Bu kişiler “Der-Beyân-1 Süleymân-1 Havas” yani Süleymân'ın ileri gelen memurları başlığg altında metinde verilmiştir. Buna göre Sâm-süvâr'ın kürsüsünün yanında edeple duran 12 melik, her yılın sonunda tuttukları defterler ile hesap vererek Hz. Süleyman'ın gelir gider ve iâşesine bakmaktadır.

Hz. Süleymân'ın tahtının ne kadar muazzam olduğunu göstermesi bakımından bahsi geçen bu 12 melikin hepsinin emri altında üç bine yakın köy, altmış altı pare şehir ve kırk sekiz pare de vilâyet bulunmaktadır. Bu meliklerin isimleri de eserde hicri takvim aylarına göre verilmiştir. Bu isimlerin aylara göre verilmesinin yanında, Hz. Süleyman'ın köylüsü, damadı, güveyi gibi yerel söyleyişlerde hala kullanılan ifadeler kullnılmaktadır. Eserde, bu ifadelerden örnek vemek gerekirse:

“......beşinci Cumâzi’ye'l-evvel ayında Ehîmâis Nâftâlî ki bu melik eserde Hz. Süleymân’ın “köylüsü”(hemşehrisi) olarak geçmektedir. ... eserde bu kişi de Hz. Süleymân’ın "güyeğisi” yani damadı olarak geçmektedir, sekizinci şa'bân ayında Şem'i bin A'lâ, dokuzuncu ramazan ayında Gûr bin Avri ..." 
Metinlerde bu on iki melikin bulunduğu yerin alt kısmında yardımcıları ve diğer vazifelilerin oturduğu belirtilmektedir. Bahsi geçen yardımcılardan Benâyâhû bin Yehuyâda Azunîran bin Evdâ "haraç defterini yazan serasker” olarak, Azır Yahı bin Nasen "hazine başı” olarak, Mâl-ı Emnûn, Ezir yahû bin Şî̧â ve emir Sadık bin Şibşâ ise "divan kâtibi” ve "hazine yazıcıları" olarak, Ahi Şer "kilerci başı” olarak, Navûl bin Nâsan âlimlerin emiri olarak, Kil'ad-1 Barçalı "kapıcılar kethüdâsı" ve Câbud bin Nâsan ise "Çavuşbaşı”" olarak görev yapmaktadırlar. Buradan da anlaşılıyor ki Hz. Süleyman ve etrafında; sistematik devlet yapısının yanında, sosyal hayatın da bir düzen içerisinde yaşanılmasını sağlayan görevliler bulunmaktaydı.

Hz Süleymân'a bağlı meliklerden birisi de Baalbek şehrinin meliki Baalbek’tir. Hz. Süleymân'ın dostluğunu kazanmak için ona kendi tavlasında bağlı bulunan atlardan birisini göndermiştir. Hz. Süleymân buna çok sevinmiş, bu atların nereden geldiklerini araştırmış, Tavûs-1 Kudsî ise bu attan daha güzel atların yeryüzünde bulunduğunu Hz. Süleymân'a bildirmiştir:

“Süleymān Ĥażretine Ǿaleyhi’s-selām çoḳ armaġanlar ve tuĥfeler gönderdiler meger ki BaǾalbek melikinüñ tavilesinde bir ћāś Ǿarabị atı var idi ki miŝlini çeşm-i felek görmemiş idi ve ġāyet yavuzlı̀̇ından kimesne binemedügi acilden Süleymān Nebịye göndermek maķśūd idindi vezịi Sermedịyle Süleymān Ĥażretine gönderdi alup nažarına getürdi.”

Sosyal hayatın esere yansıyan taraflarından yapılabilecek çıkarımla, canlı ve sistemli bir yaşamın yani saray yaşamının tüm varlığı eserde gözlenmektedir. Hz. Süleyman'ın etrafında devlet yaşamında ve sosyal hayata nizam veren yardımcılar olduğu, isimleriyle birlikte verildiği yukarıdaki örneklerde görülmektedir. $\mathrm{Bu}$ yardımcıların neden aylara bölünerek görevlendirildiği üzerine bir çıkarım yapmak zor olmakla birlikte, sürdürülebilir bir nizamın varlığı kesin görünmektedir.

\section{Giyim-Kuşam}

Giyim ile ilgili olarak eserde sadece Hz. Süleyman'ın giyimiyle ilgili birtakım bilgilere rastlanmaktadır ve bu giysilerin de daha çok peygamberle ilgili olduğu görülmektedir:

Eserdeki anlatıma göre Hz Süleymân tahtına oturduğunda üzerinde giydiği elbiseler şu şekildedir:

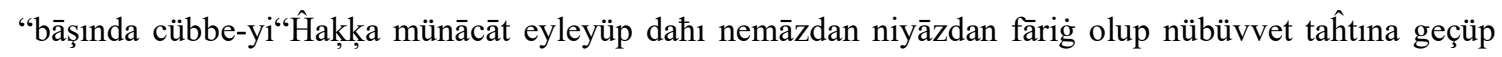

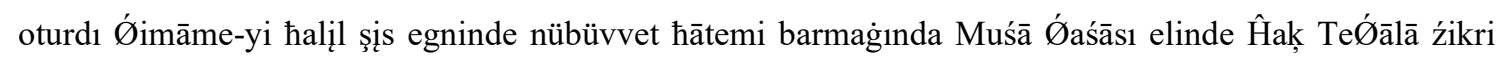
dilinde" (HK, 1c, 35).

Hz. Süleyman'ın giydiği elbiseler metinde hemen hemen aynı şekilde verilmektedir. Buna göre; başına imâme-i halil takmakta, üzerine Şit'ten kalma bir cübbe giymekte, belinde kemer, Musa peygamberin asası da elindedir. Kendinden önceki peygamberlerin giydiği ve takındığı kıyafetleri Hz. Süleyman da kullanmaktadır: 
“...Ǿimāme-i ћalịl bāşına alup cübbe-i şit egnine śālup ādem-i śafị śāçıp beline kemer ķılup Mūsị Ǿaśāsın

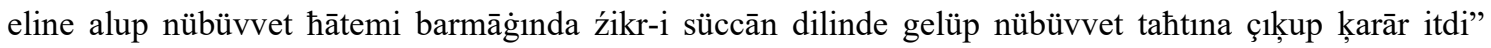
(HK, 1c,73).

Aşağıda yine farklı bir anlatıda aynı elbiseleri giydiğinden bahsedilmektedir:

“nite Şiŝ Ǿabāsın evvel çignine śālup Halil Peygāāmber Ǿimāmesin bāşına vurdı ve Ādem-i Śafị śāçın biline kemer bag̉ladı ve Nūĥ Nebị cübbesin egnine śāldı ve Musa-1 Kelịm naǾlının ayag̉ına giyüp Ǿaśāyı eline aldı" (HK,1c,139). "Kösfend cinsị üzerine turan melek-i müvekkel dahı ķıŗ̧ bāş ķoyun iletdi ve yüñlerini ķırḳmaķ ve egirmek taǾlįm itdi andan havvā ķoyun yüñin egirdi Ādem-i Śafịye ve kendüzine bir Ǿabā göñlek itdi şol tāriћde Şiŝpeyġāmber žuhūra gelüp toḳıdı andan evvel Ǿabā ķaftān kimse giymedi andan śoñra Ādem-i Śafị Ǿaleyhi's-selām Mekke yirine geldi Mekkeyi emri haķ ıla yapup ziyāret ḳıldı nite kim kelām-1 ķadįm içre K59” (HK,1c, 126).

Öznesinde Hz. Süleyman olan eser, giyim kuşam konusunda da yine onun ve kendinden önceki peygamberlerin giyim kuşamından ve kumaşın ne zaman ve nasıl oluşturulduğuna dair bilgiler vermekten öteye gitmemektedir. Ancak sadece Hz. Süleyman üzerine dahi olsa giyim konusundan bahsedilmesi eserin zengin kültürel bir doku ile işlendiğini göstermektedir.

\section{Sofra ve Yiyecekler}

Sofra ve yiyecekler bahsinde de giyim konusunda olduğu gibi, Hz. Süleyman ve onun sofrasının özellikleri daha çok ön plana çıkmaktadır. Bir gün içinde pişen yemekler ve yemeklerin yenildiği kaplara dair bilgilere bazı bölümlerde rastlanmaktadır:

Hz. Süleyman, Kahrâm-1 Zengî Sâmsüvar'ın otağına geliyor ona sofra hazırlarlar. Ancak bu sofranın vasfı metinde ne yenilip içildiğinden daha çok sunulmasından/ hazırlanmasından duyulan minnete yönelik dualar üzerinedir:

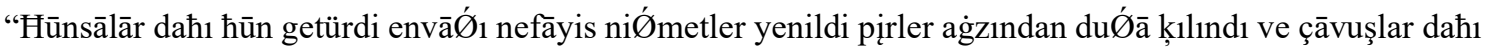
ki alkış virdiler śāfdan śofra'i dürüp götürdiler sükker şerbetlerin getürüp içdiler sözden söz çıķup” (HK,1c, $50)$.

Süleymân'ın dergâhında yemeklerin kimlere yapıldığg, daha çok destansı bir anlatımla dile getirilmiştir; içine“on deve sığan” kazanlar, bir seferde içinde "yüz koyun pişen kazanlar gibi. Bunun yanında yemeklerin nerede saklandığı, piştiği ve bir günde pişen yemeklerin nasıl kaplarda verildiği, bu kapların ebatları da aşağıdaki örneklerde anlatılmaktadır:

"kiler ve anbār ve cemįø źahire nevǾiyle śaķlamag̉a hucurāt vardı biñ bir ümmetüñ behāyim ve hayvānātuñ ve haşerātuñ źahiresinden ve mürḡānuñ hubūbātından ve yırtıcı cānavarlaruñ yidügi bālıḳ etinden gayrı

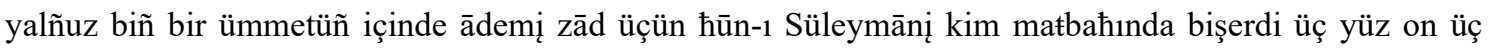
ķazķānlar vār ıdı kim ehremenler ānı ocak tāşından düzmişler idi ve her bir ķazķānuñ içinde on deve śı́gardı ve ķazķān var idi ki içinde yüz ķoyun bişerdi süryānị ķavlince Ǿimrānịler kitābında şöyle gördüm ki her gün Süleymānuñ matbahında Ǿarap mužırrı hisābınca otuz mud simịd unı ћarc olırdı ve altmış mūt harcı ondan ġayrı ve günde iki nevbet hūnį çıķardı her nevbetde on śıgıır ve yigirmi inek ve on deve ve yüz ķoyun 
bişerdi şikār etinden ve besleme horusdan gayrı ve on iki biñ zerrịn kemer ķol çāşnıgịr ve ārdı ve ķırķ biñ Łavile atları vār" (HK,1c, 150).

Yine Hz. Süleyman'in kilerinde bulunan yemeklerin özellikleri ve hangi tür kazanlarda pişirildiği de aşağıda verilmektedir:

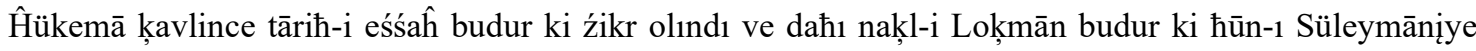
günde biñ vaķiyye tuz harc olurdı ve ol ķazķānları ki dịvler ocaķ tāşından işlemişlerdi her ķāzķāna ķırḳ

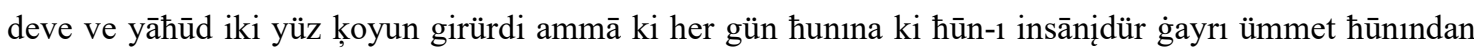
ġayrı ķırḳ deve yüz śıġır ve biñ ķoyun bişerdi ve Ķuds-i Mübārek kịlesi ile biñ mevt on simįd çörek olurdı

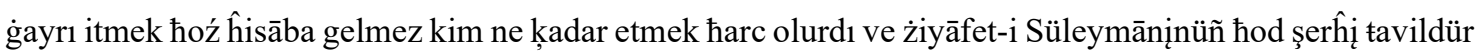
inşā’llāh-1 TeǾālā Süleymān Ĥażreti Ǿaleyhi's-selām Mekkeye vārduġı hịnde cemịǿ eşyāyı żiyāfet itse gerekdür ol hịinde hūn-1 Süleymānị tafśsil birle temām źikr itsek gerekdür (HK,1c, 151).

Aşağıda da tatlı ve şerbetlere yönelik bilgi verilmektedir:

“...bir tarafda daћı aşbāzlar envāǿ dürlü dürlü loḳmalar bişürüp śātarlardı ve helvāyịler dahı Ǿasel-i musaffādan Ǿalā dịni helvā bişürüp şehde şekkerler ķatarlardı ve şerbetçiler fuḳāói bardagiın zer-nigār iderlerdi. Sükkeri Mıśri ezüp cüllāba ķatup şerbet ihżāâr iderlerdi ol śanem diler ballar güneş talǾat ve mehliḳālar fuķāó́i bardag̉ın ag̉zına alup ki leb ber leb emerlerdi Ǿuşşāḳ-1 miskịn ķarşusına geçüp hayrān olup ag̉ız açup ķatresine...”(HK,1c, 151).

Örneklerden görülüyorki, Hz. Süleyman'ın mutfağı sadece insanlara değil canlıların tamamına hizmet etmekteydi.

\section{Halk Hekimliği}

İnsanın varoluşuyla yaşıt olan halk hekimliği ve geleneksel uygulamalar, günümüzde, "kültür mühürümüzün izlerini taşıyan” yaşayan tarih olarak değerlendirilmektedir. İnsanoğlu hastalıklardan korunmak ve hastalandığında iyileşmek için sihir, büyü ve dinden yardım beklemiş, yaşam boyu edindiği deneyimlerden yararlanmıştır. İnanılan ve güven duyulan bu etmenler halk hekimliği uygulamalarının yaşama geçirilmesini kolaylaştırmış ve insanlık tarihi boyunca sürmesini sağlamıştır (Artun, 2007: 202). Halk hekimliği başlığı altında değerlendirilebilecek örnekler hem hayvansal tedavi yöntemlerine yönelik hem de eserde tarihi bir şahsiyet olarak sıkça görülen Lokman Hekim'in yaptığı tedavi yöntemlerine yöneliktir:

Fisaguras Hekim, Süleymân dergâhında kendini savunurken iki kişiyi görmüş ve bu gördüğü kişilerin üç gün içinde öleceklerini belirtmiştir. Dediği kişiler hekimin söylediği saatte ölmüştür. Hz. Süleymân bu olayın hakikatinin ne olduğunu sormuş; Fisaguras da ölenlerden birinin içinde bir kurt 
olduğundan bunun gut hastalığına sebep olduğundan söz etmiştir. Gut hastalığına mübtela olan kişinin de kırk günlük ömrünün olduğunu, kendi ilmiyle o kişinin kaç gün yaşayacağını bilebildiğini söylemiştir:

\begin{abstract}
“Ĥakịmü'z-zamān ol iki kişinüñ ölecegin neden bildüñ cevap virdi ki yā Süleymān ol ķahķahāyla gülenüñ ķarnın yārup yüregi içinde bir ķurd vārdur çıķārup getürsünler defǿi yarıp çıķarıp hakịm nažarında ķodılar Ĥakịm eyitdi yā nebịyu'llah bu ķurd her kimüñ ki cisminde zükāmdandur ise ķırķ gūne dek iћtiyārsuz ķahķahayıla ol kişi gülmesin k ķomaz ammā vārdug̉ınca āǾvāzı bu gut olur ilānı güldüginden onı bog̉ılur tasavvur iderler ammā ehl-i hikmet nazar-1 pāk ile k̦ırḳ günüñ k̦āçı geçmiş ve bāḳi ne k̦almışdur bilür zịrā ki bu ķurd vakti ki yürekde durur ķırķ gün temām olıncaya dek yüregi delüp içine girer ādemị der ü hāl ölür pes önünden bildüm ki dilegüm miķdār günde ölse gerek zịrā ki İdrịsüñ hikmeti üzere dilegi olsa gerek...”(HK, 1c, 35).
\end{abstract}

$\mathrm{Bu}$ olayın devamında da kişinin gözlerinden kaç günlük ömrünün olduğunun bilinebildiğini belirtmiştir:

“...ve dahı ol kişünüñ ki gözlerine nažar itdüm gördüm ki şarāb ānuñ yüreğin yāķmış pes hikmet-i mucebince gözleri nişānesinden bi-kavl-i İdrịs Ǿaleyhi’s-selām maǾlūmum oldı ki üç gün Ø̋ömri vār lābud olısardur hayr u şerden itdügin bulısardur...”(HK,1c, 35).

Eserde bazı canlıların ve bitkilerin çeşitli hastalıkların tedavisinde kullanıldığına dair anlatılar da bulunmaktadır. Bunlardan biri de Samsüvar ile Dermayus Hekim arasında geçen hikâyedir: Samsüvâr gergedanserler ile savaşa giderken yolda garip yaratılışlı bir hayvan görmüştür, bu hayvanın bir hikmeti var mıdır diye sormuştur? Dermâyus hekim de bu garip yaratılışlı hayvanın kitaptan, insanda şifâ olarak neye iyi geldiğini bulur ve söyler:

"Sām eyitdi Ǿacep bu cānavaruñ insanā nefǿi vār mı ola didi andan Dermāyūs Ĥakịm eyitdi İy pehlüvān1 cihān Ĥaķ Sübhāne ve Teǿālā cümle eşyāyı kim ћalḳ idüpdür her birinüñ bir dürlü nefói vārdur velị Ǿilm ile bilmek gerekdür diyüp havāś-1 ĥyvān kitābın eline alup ol cānavaruñ śuratın bulup Sāmsüvāra beyān itdi didi kim iy pehlüvān-1 cihān bu canavaruñ insāna nefói budur kim bir kişi bu cānavaruñ yüregin kebāp ḳılup yise ġāyet cigerdār ola şöyle kim hayvāndan insāndan hịç ķorḳmaya bāķịsin Ĥaķķ teǿalā bilür diyüp ћāmūş oldı Sām-u Süvar ol canavaruñ nefóin bilüp buyırdı yüreg̉in alup keŝdiler giceye ķarşu bargāha gelüp yiyüp içüp yatdılar çịn-i seher göç ķılup gitdiler...”(HK, 1c, 63).

Öküzlerin yaratılışı ile ilgili anlatılan mitolojik kaynaklı hikâyede bu hayvanların kimi özelliklerinin insanlara faydalı olduğunu ve nelerde kullanılacağını bildirmektedir. Deniz sığırının etinin dimağa faydası vardır ve metinde de geçtiği şekliyle denizin dibinde biten anber otu ile deniz sığırının şifâ olarak aynı özellikler gösterdiğini bildirmektedir:

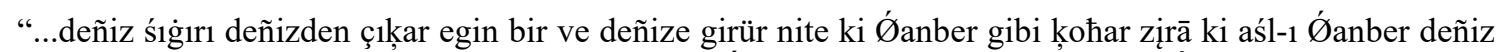
dibinde biter bir otdur velākin deniz śig̀ıırınuñ döşi Ǿanber fā'idesin ider dimag̉a ve havāsa ve ķalbe ḳuvvet virür ve dahı rivayet-i śahịh budur ki Ø̋anber bir otdur deñiz dibinde biter Ĥūt-1 ǾAnberān yir dahı teze ki

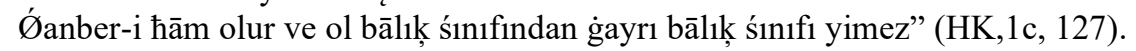

Sivrisinekleri evden kovmak için camız etinin buharının faydalı olacağı belirtilmektedir. Eserden elde edilen bilgiler doğrultusunda eğer bir evde camızın eti haşlansa ve bu haşlanılan etten çıkan buhar eve yayılırsa, o buhar sayesinde evde sivrisinek dahil hiçbir haşeratın kalmayacağı anlatılmaktadır. Haşerat olarak sadece "bit”lerin olabileceği bunun çözümünün ise camızın yağı ile tuzun karıştırılıp konması halinde bitlerin de yok olacağı anlatılmıştır: 


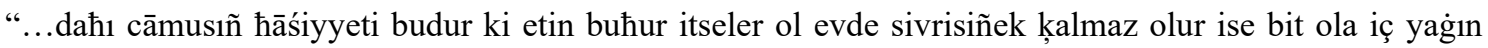

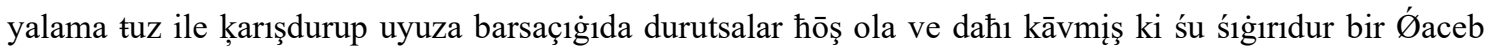
cānavardur ki gūta yir yaǾni ki kendüzinden gevşer kimse bilmez ki o zahịrenüñ’(HK,1c, 127).

Aşağıda sığır cinsinin birçok faydalı özelliklerinin olduğuna dair bilgilerin anlatıldığı görülmektedir.

“...daћı yā nebịyu’llah berrị baķarda hāśśa çoķdur nite şöyle ki eger boynuzın dökseler rıbǾi istiması dutan kişiye taǾām ile yidürseler güye eger içse ķuvveti cimāó 1 ziyāde ola eger odın kendüne śu ıla ķarışdırup

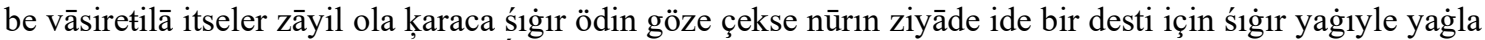
bogāāzına dek bir yire göme ķucamīǿ bize aña uşa śı̇ı̇ı źekerin ķurıdup dökse nịm bir şit yumurda üzerine

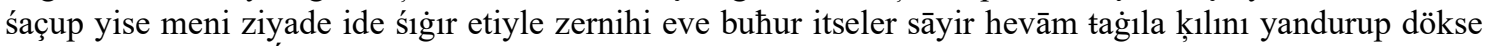
içse diş agrısın defǿ ide..." (HK,1c, 130).

Cezîre-i Hayl'den atları getirmek için Lokman Hekim'in* tavsiyesi ile bir karışım hazırlanmış ve isyan çıkaran atların burnuna sürmek suretiyle bayılmalarını sağlamışlardır. Aşağıda bayılan atları tekrar ayıltmak için sirke ile yapılan bir karışım verilmiştir:

“...ile ol yatan atlar üzerine vardılar ācı badem yāġın śarıp sirke ile ķarışdurup burunlarına tamźurdılar. Tā ki atlaruñ her birisinüñ uşāg̀ı vü irisinüñ hiss-i idrākleri bāşlarına gelüp gözlerin açup esneşdiler ve çevre yānlarında ādem görüp belikleşüp yirlü yirinden turup kişneşdiler...” (HK,1c, 155).

Hem hayvanattan hem nebatatdan yararlanarak yapılan birtakım ilaçlarla ilgili bilgiler yukarıda verilen örneklerde görülmektedir. Bu örnekler dışında halk hekimliğinin hem malzeme hem uygulama alanına dair kültürel birçok malzemeye eserde yer verildiğini de söylemek gerekmektedir. Sadece insanlar için değil, hayvanlar için de kimi karışım ve uygulamalara rastlanıldığı örneklerde dikkati çeken bir başka önemli noktadır.

\section{5. İnanışlar}

Halk inanc1, kişice ya da toplumca, bir düşüncenin, bir olgunun, bir nesnenin, bir varlığın gerçek olduğunun kabul edilmesidir. Halk biliminin ilgilendiği konulardan biri de belli bir toplumun eski dinlerinden miras alıp yaşadığı çağdaki yeni dininde, yaşam şartlarının gerektirdiğince yeni biçimler, yeni içerikler, yeni anlatılışlarla oluşturduğu inanışlardır. Halk inanışları din, âhlak kuralları gibi kesinlik ve katılık taşımazlar ve yerden yere, topluluktan topluluğa değişiklikler gösterir (Boratav, 1997: 7).

\subsection{Sihir, Tılsım, Büyü}

İslamiyet öncesi büyü kültürünün yeryüzündeki belli başlı merkezlerinden Orta Asya, Şamanizm olarak bilinen büyü din karışımı inanç sistemi, aynı zamanda Türk kültürünün de ana kaynaklarında birisidir. Büyü, iyi ve kötü sonuç almak için tabiat ögelerini, yasalarını etkileyerek, bu olayların

\footnotetext{
* Lokman Hekim'in ismi incelenilen Süleymân-nâme isimli eserde "Lokman Hakîm” şeklinde geçmektedir.
} 
olağan düzenlerini değiştirmek için girişilen işlemlerin tamamına verilen addır (Artun, 2007: 284).

Bu çerçevede Süleyman-nâme adlı eserde karşılaşılan örneklerden bir kısmı şu şekildedir:

Melik Ahmer, El-henci cinninin yanında Batlamyus ve Yemlun hâkimini gökte birlikte uçarlarken görür. İnsanların böyle cin gibi uçup gideceklerini tahmin etmediğinden bunların şeytan-1 lain olduğunu anlar ve Zebur ve Tevrat'tan yedi ayet okuyup Hz. Süleymân'dan öğrendiği şekilde üzerlerine üflediğinde Şeytan ile Hannas kaybolup gider:

"bunda kalacak deg̈̈̈l ve bir dahı insān dem çeküp cin gibi gök yüzinde uçacaḳ degül vār ise bu Şeytān-1 LāǾindür diyüp Hażret-i Süleymāndan Ǿaleyhi's-selām ta'lịm olduğı yidi āyet-i Tevratı ve yidi āyet-i Zeburı oḳuyup Allaha tekbịr evvel Ādem ahir Muhammed śalavātu'llāhi aleyhim ecmaǾịn gelmiş gelecek mürsel peyġāmberler ervāĥnı śalavāt virüp ol re'įs-i vesvās ve racįm- i Hannās üzerlerine oḳıyup üfürdi berekāt-1 Zebūr ayeti ve Tevrāt yetmiş yıllıḳ yolu ḳaǾrị zemịne ḳahr olup Şeytān-1 LāǾinle Hannās-1 bịdịn gitdiler" (HK,1c, 20).

Lokman Hakîm, Şehzade Ferruh'un öldürülmesi olayında masum olduğunu ispatlamak için iki tane âşığı yanına getirmelerini ister. Onlara kırkar miskal zehir yedirip yılan ve akrebe sokturarak büyü yaptırır. Büyünün onlara tesir edip etmeyeceğini anlamak için iki aşığı bir odaya koyarlar ve onların zina etmesi sağlarlar. İki âşık birbiriyle zinâ ettiği için de büyü etkisini gösterir ve ikisini de öldürür:

“Ĥakịm eyitdi size ki zehr-i kātil yidürdüm ve i’lana Ǿakrebe śokdurdum eger kim bu maǾşukalarıñzla murād yatmagısa öpüp ķavucuñ ammā ki zināya riżā virmezem eger ki zina ḳılasız zehr size žafer bulup te'șịr idüp helāk ider anlar dahı zina ķılmamag̉a himmet itdiler andan hakịm anları halvet ķoyup kendü

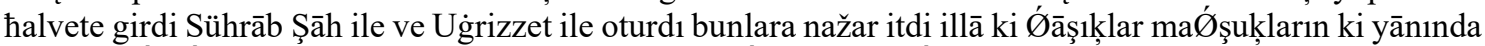

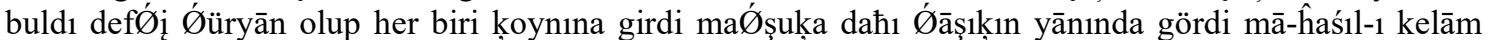
ķı́śayı dırāz ķılmayalum Ǿāşık ki maØ̊şuķ halvet bula ve ķurt ki ķuźuya furśat bula hịç śabr mümkin olmaz lā-cerem anda śabr itmek hayal-i muĥ̄ldür." (HK,1c, 27).

Lokman Hakîm cinlere birşey yaptıracağı zaman daire çizip cinleri büyülemekte ve sonra ne isterse onu yaptırmaktadır. Âşıkların sevgililerini getirtmek için de yere bir daire çizmiş ve cinlere istediklerini yaptırmıştır:

“ĥkịm dahı dā'ire çizüp teshịr-i cin ķılup emr itdi kāfir hammām cinüñ Ǿavratıyla tersā-yı tacir ḳızını örtüsi döşegi ile cinnįler götürüp getürdiler” (HK,1c, 26).

Lokman Hakîm ve Fisaguras Hekim simya ve cifr ilimleriyle meşguldürler. İhtiyaçları olduğunda simyâ ilmine başvurmuşlardır. Daire çizmek de bu noktada cinlere istediklerini yaptırmak için kullandıkları bir yöntemdir. Cinlere birşey yaptıracakları zaman daire çizip cinleri ortasında tutsak etmekte daha sonra da bu cinlere istediklerini yaptırmaktadırlar:

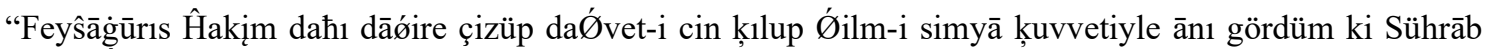
Şāhuñ ĥammām yolında gördügüm ḳızını örtüsü ve döșegiyle ve nuḳl ve șekkeriyle ve bāşı ucında yānan altūn şamǿdān ve ayāğı ucında yanān gümiş şamǿdān birle götürüp nažaruma getürdiler” (HK,1c, 29).

Fisaguras hekim mâsum olduğunu kanıtlamak için bir ölüyü konuşturmuş, ölünün içine ilm-i simyâ ve büyü kuvvetiyle bir cin sokmuş, sonra da ona çeşitli sorular sormuştur. Ölü de tıpkı bir önceki olayda olduğu gibi konuşmuş ve yerinin iyi olduğunu dünyaya tekrar gelmek istemediğini belirtmiştir: 
“Süleymān gażaba gelüp ķaķıdı hakįm eyitdi şāha k̦āķımaġıl peyġāmbersin saña gażāb yaraşmaz benüm

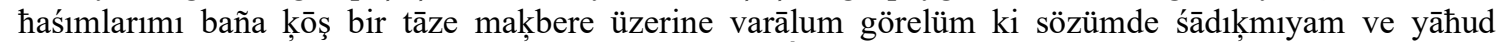
kāźibmiyem diyüp bir tāze maķbere üzerine varup Ǿilm-i simyā ķuvvetiyle bir cinne hükm idüp ol meyyitüñ içine girüp ķaldurıp ag̣zından haber virdi hakịm śordu ki ne vaķtden berü öldüñ cevāb virdi ki dört yıldur andan hakịm didi ki diler misin ki seni Ĥaķ TeǾālādan dileyün Ǿömr vire ve yāhud yirüñe hoşnūdmısın cevāb virdi ki yirüme hoşnūdam duǾā k̦ıl ki yine Ĥaķķa ulaşam diyüp cinnị meyyit cesedi içinden haber virdi hakịm duǾā ķılur gibi eyitdi cini meyyit içinden çıł̧dı meyyit kabre düşdi ķabrini müteĥhakkim idüp hakįmlere gitdiler gelüp bu olan ķażayāyı Süleymāna naķl itdiler” (HK, 1c, 31).

Hz. Süleymân da yeri geldikçe sihir ve tılsıma başvurmuştur. Fisaguras hekimi konuşturmak için Fisaguras'ın(Pisagor) azasındaki cin ve melekleri dergâhına çağırır, bunu teshir-i cin kuvvetiyle Allah'ın isimlerini söyleyerek yapmaktadır:

“....nübüvvet ћāteminüñ üzerinde yed-i kudretiyle mestūr olan esmau'llāhıñ teshịr-i ins ismini okıyup insān üzerine müvekkel olan meleki daǿvet itdi. İżn-i Yezdānį hükm-i süccānị muǾciz-i Süleymānị birle müvekkel insān Şerātāyil Melek hāàı̇r olup gelüp Süleymāna selām virüp göründi ne buyurursın yā nebịyu'llah diyüp emre mutįǿ olup turd1...”

Hz. Süleymân Kibriyâ'il meleğe elindeki tılsımın ne olduğunu sorar, o da tüm hayvanlara onunla hükmederim vb. açıklamalarda bulunur. Buna göre tılsımın en önemli faydalarından biri, eğer bir kişi o tılsımı suyun içine koyup içse, içen kişi vücudundaki tüm hastalıklardan anında şifa bulur. Tılsımın orjinal hali de metinde verilmektedir:

"Ĥakịm ķavlince Kibriyāyịl melek-i müvekkel baķara böyle diyüp baķar cinsinüñ sebeb-i tilḳatin beyān idicek yine Süleymān Ǿaleyhi's-selām suǿāl itdi ki bu elüñde münaķķaş olan levhüũñ hāśśası nedür cevāp virdi ki yā nebìyu'llah bu levhüñ içindeki yed-i ķudret ile mestūr olan tılsımātuñ hevāśı berekātiyle cemị̂ baķar cinsine hükkm iderem ve benüm taht-1 yedümde niçe yüz biñ tekvịn vardur ki emrüme çākerlerdür bu edǾiiyye berekātında ve her kim bu tılsımātı ķamer ŝevr burcında iken yazup kendü ile götürse sebāǿdan żarar gelmeye eger ki Behāyim hastalansa misk ü zaǾferānla yaşıl çanagia yazup śuyın içüreler şifă bula bi-

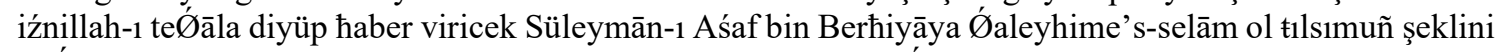
edǾiyā nüsћanesine naḳş itdi müslümānlara fă’ide içün hāze duǾă’’ inest”(HK,1c, 126).

Hz. Süleymân'ın çevresinde üçler yediler kırklar olarak ifade edilen ruhânî varlıklar da her dâim hazır bulunmaktadır. Hz. Süleymân bir şeyin olmasını Allah’tan isteyeceği zaman onları da yanında bulunmaktadırlar. Birlikte temiz sudan abdest alıp birlikte dua etmektedirler:

Sührāb Şāh ḳızı Hümā tabutın ķoyup on iki biñ enbiyā vü on iki biñ evliyā vü on iki biñ Ǿulemā vü hükemā vü etķıyā aśfiyā birle ķutbü’l-aķtāb g̉aybü’r-ricāl üçler yediler ķırḳlar ve tabaķāt erenleri Hiżr İlyās Peyġāmber ile hāǎžr olup pāk śudan āb-dest aldılar.

Örneklerde de görüleceği üzere halk inanışları ve memoratlar olarak adlandırılan birçok anlatı eserde yer almaktadır. Anlatılar daha çok doğaüstü güçlerin yönlendirilmesi ve kontrol altına alınmasına yönelik uygulama ve ritüellere yöneliktir. Dini motiflerle süslü bir edebi eserde bu türden anlatılara rastlamak olağan olmakla birlikte tarihi şahsiyetleri de bilinen kahramanların simya ilmini bilmeleri dikkat çekicidir. Son örnekte ise halk kültüründe formülistik sayılar olarak bilinen ve dini anlatılarda sıkça görülen üç, yedi, on iki ve kırk sayılarının varlığı görülmektedir. 


\section{GEÇİŞ DÖNEMLERI}

Bilindiği gibi insan yaşamının başlıca üç önemli “geçiş dönemi” vardır. Doğum, evlenme, ölüm. Herbirinin kendi bünyesinde birtakım alt bölümlere ve basamaklara ayrıldığı bu üç önemli aşamanın çevresinde birçok âdet, töre, tören, âyin, dinsel ve büyüsel özlü işlem kümelenerek söz konusu "geçiş"leri bağlı bulundukları kültürün beklentilerine ve kalıplarına uygun bir biçimde yönetmektedir. Bunların hepsinin amacı da kişinin bu "geçiş" dönemindeki yeni durumunu belirlemek, kutsamak, kutlamaktır (Örnek, 2000: 131). Geçiş dönemlerinde kümelenen âdetler, gelenekler ve törenler geleneksel kültürün ana bölümlerinden birini oluşturur. Bugün uyulan birçok âdet ve inanma kalıpları, eski Türk inançlarının günümüze gelmişşsekilleridir (Bars, 2015: 355). Bir çoğu ritüel işlevini kaybetmiş eski Türk inanç kalıntıları, âdet adı altında yaşamaktadır. Bahsi geçen bu "geçiş" dönemlerinden Süleyman-nâme’de “düğün” ve “ölüm”e dair örnekler görülmektedir. Birincisinde düğün ve kız isteme ile ilgili verilerle karşılaşılmaktadır. Ölüm kısmında ise ölüm sonrasına dair yapılan uygulamalardan bahsedilmektedir. Ayrıca, sözlü hukuk sistemi ile birleşen “kısas kavramı ile kan parası” ve "kara haber” olgusu da “ölüm” başlığı altındaki örnekte kendine yer bulmuştur.

\subsection{Düğün}

Eserde, düğün ve kız isteme geleneği ile ilgili bilgilere rastlanılmaktadır. Ferruh Şah'ın öldürülmesi olayında iki âşık diriltildikten sonra Hümâyı Ferruh'a istemişler, babası verince de üç gün üç gece düğün yapmışlardır:

"Süleymān turdı Süleymān Ĥażreti Allahuñ emri birle Sührāb şāh ḳızı Hümāyı Efrāsiyāb ḳarındāşı og̉lı şehzādeǿi Ferruћa istiyordu. Sührāb Şāh daћı ayāg üzere turup duǾā ķılup eyitdi ki yā nebịyu’llah Allahuñ emrine riżā virdüm her ne ise yirine getürüñiz didi andan ol arada Dāvud Peygāāmber şerị́øatınca Süleymān nikāh idüp üç gün üç gice dügün olup Hümāyı şehzādeye virdiler.

\section{2. Ölüm}

Ve'd Dünya'nın hocasının El Henc cinninin askerleri tarafından öldürülmesi üzerine dini adetlere göre ölüyü yıkayıp kefenlemişler ve üstünü toprakla örtmüşlerdir. Ölü yıkama ve toprağa gömme adetleri günümüzdekiyle hemen hemen aynı özellikler göstermektedir. Matem tutma geleneğini de vardir:

“Ve’d-dünyā daћı hocāsını ķullar depeledügine te'essüf idüp cismini pāk śuyla yuyıp kefen śarub Ǿādet-i ķadịm üzere ķara yirüñ ķarnunı yārup sinlegim düźetdiler. Andan peygāāmber şerịǾatınca VeǾd-dünyānın hocasını kefenleyüp hāk içinde defn itdiler ve mātem tutdılar...(HK,1c,10).” 
Sührâp Şâh’a kızının ölüm haberini bir güvercin getirmektedir. Buna göre Sührâp Şâh’a gelen güvercinin ayağında siyah bir mektup vardır. Kara haberin kara bir nâmeyle gelmesi eski bir adet olarak değerlendirilebilir:

"virdi eyitdi ki yā şah-1 cihān bu nāmeyi gügercin getürdi ayaġından alup nazaruña getürdüñ ammā ki hayr habere beñzemez diyüp nāmeyi eline virince Sührāb Şah siyāh nāmeyi görüp mührin götürüp oķudı āh idüp tācın yire urdı"” (HK,1c, 25).

Şehzade Ferruh'un katledilmesi olayında Hz. Süleymân Lokman Hakîm’i divanında yargılamıştır. Lokman Hakîm'in haksız çıkması durumunda ya kısas yapılması gerektiğini ya da kan parasını ödemesi gerektiğini söylemiştir. Kısas ve kan parası âdeti uzun süre devam etmiş adetlerdendir:

“Loḳmān Ĥakịm hāàżr ḳılup eyitdi ki yā hakịm ez-zemān sözüñ saāıḳ olmādı hikmete mutabıḳ gelmedi şehzādeye kı̣rḳ dirhem zehr yidürdüñ ve ilāna Ǿaķrebe śoḳdurdun nesne olmaz diyü daǾvi kıllduñ şimdiki hâ̄lde şehzāde Sam eŝerinden vefât itdi. Musā peyġāmber șeriǿatınca ve Tevrāt hükmince Allah buyruġınca ve atam Dāvud şeriǿatınca ķanlusın ĥükm idüp şehzādenüñ anası Ug̉rizzet eline virürem yā budur ki saña ķıśaś iderler yā budur ki bunlaruñ ile ķān bahāsın virüp riżālaş veyā hoź şeriǿatdan taşra iş itmek yā hakịm ez-zemān elümden gelmez...(HK,1c,24).”

Fisaguras Hakîm'in Ferrûh ve Hümâ'yı zehirlemesi olayında iki âşık da ölmüş, yapılan zehir ölülere dokunanlar ve ölüleri yıkayanlar da dâhil çevresindeki herkesi öldürmüştür. Hz. Süleymân bu katli kimin gerçekleştirdiğini araştırır. Tüm kanıtlar Fisaguras Hakîm’i işaret etmektedir; fakat o bu suçlamaları kabul etmez. Hz. Süleymân suçluları bulmada çaresiz kalınca Tavus-1 Kudsî adlı melek Hz. Süleymân'a gelip mezardakilere sormaları halinde Allah'ın (c.c.) izniyle kendilerini kimin öldürdüğünü söyleyeceklerini bildirir. Hz. Süleyman çevresindekileri de alıp âşıkların yattığı mezara giderek mezarın başında âşıklara, katillerinin kim olduğunu sorar, onlar da olayın aslını anlatırlar:

“Ĥükemā ḳavlince çünki ale’ś-śabāĥ oldı on iki biñ muǾcizātı žāhir olmış enbiyā birle ve on iki biñ vilāyete ķadem baśmış evliyā ile ve ķutbü’l aḳtāb ile üçler ile yediler ile Hiżr Peyḡām-berle ve İlyās Peyġām-berle cemǾi vüzerā vü ümerā ile ve hükemā vü Ǿulemā ile şehzādeniñ ķabri üzerine varup pāk śudan āb-dest alup iki rekǾat hāacet namāzın ḳılup Hıżr Peyḡām-ber müǾeźźinlik idüp Süleymān Peygāām-ber hażrete imāmlıķ idüp namāzdan niyāzdan fārig olup el götürüp şehzādenüñ hayātı içün duǾā diledi melekūtü'ssemāvāat enbiyā vü evliyā aśfiyā birle Süleymān dứā diledükçe āmįn didiler. Ĥaḳk Teøóāā celle ve Ǿalā Süleymān dứ̋āsın ķabul idüp şehzāde cismine cān virüp ķabir yarılup şehzāde içinden turıp Süleymān Ĥażreti anı görüp eyitdi ki Ya şehzāde baña haber vir ki senüñ ölümüñe sebeb nedür (HK,1c,29).

Allah, Süleymân'a isterse ölüleri de diriltebileceğini Tavûs-1 Kudsî vasıtasıyla bildirmiştir. Tavûs-1 Kudsî, Hz. Süleymân'dan Ferrûh'la Hüma'nın dirilmesi için kefen ile birlikte alınıp Hz. Süleymân'ın dergâhına getirilmesini daha sonra da iki rekât namaz kılmasını ve Allah’tan ölülerin dirilmesi için dua etmesini bildirmiştir.

“Eyitdi ki yā nebịyu'llāh Melik Aĥmere hükm eyle Sührāb Şāh ḳızı Hümāyı merḳad ile kefenini tabut ile nažaruña getürsün ve Temhūriş melege hü̈km it Uġzirret og̉lı Şehzāde Ferrūh tabut ile kefen ile iĥżār itsün. İki rekǿat ĥācet namāzın ḳılup anlaruñ ĥayatı içün dứ̆ā ḳıl müstecāb idem ḳıḳar yıl Ǿömr virem ve birbirine virüp anlardan nesl getürem on dört biñ Ǿáśị tersālaruñ haşre neşre inkār iden kāfirlerüñ ịmāna geldügi cihetden Fị̂sāgūuras Ĥakimüñ günāhın daћı Ǿafv itdüm” (HK,1c,47). 


\section{SONUÇ}

Yazılı kaynak olarak 15.yy'dan günümüze taşınan kültürel kodların ve kültürel unsurların tespit edilmesine yönelik yapılan bu çalışmada, halk bilimi unsurları içerisinde Süleyman-nâme'nin 67 ve 68. ciltlerinin Latin harflerine çevrilmesiyle elde edilen metin incelenmiştir. Ele alınan metin ilk izlenimde Hz. Süleyman'ın hayatı etrafında gerçekleşen dini hikâyeler şeklinde görünse de aslında folklor araştırmaları için önemli bir yazılı kaynak özelliği göstermektedir. Giriş ve kavramsal çerçeve ve sonuç kısmından oluşan makalede; sosyo-kültürel hayata, halk hekimliğine, inanışlara ve geçiş dönemlerine dair örnekler tespit edilmiş ve her biri ayrı başlıklar altında değerlendirilmiştir. Görüleceği üzere eserde karşılaşılan her örnek ana kahraman $\mathrm{Hz}$. Süleyman etrafında şekillenmektedir. Hz. Süleyman'ın anlatımı, giyim-kuşamı, etrafındakiler, sofrası vb. başlıklarda halk kültürüne ait pek çok motifle karşılaşılmaktadır. Bu örnekler çok olmasına karşın bir makalenin sınırlarını aşmamak adına sınırlı tutulmuştur. Halk edebiyatından birçok öğeye rastlanılan bu çalışmada, edebi eserlerde halk kültürüne ait verilerin tespit edilmesine odaklanılmıştır.

“Hz. Süleyman ve çevresindekiler” bahsine bakıldığında Hz. Süleyman'ın tahtgahının ne kadar muazzam olduğu, tahtgahda hazır bulunan “damat", "güvey” gibi kişilerin tafsilatıyla anlatıldı̆̆ı, bu kişilerin vefa, sadakat vb. özelliklerinin akrabalık bağları ile ilişkillendirildiği görülmektedir. “

Giyim kuşam” başlığında Hz. Süleyman'ın kendine has giysileri tafsilatıyla anlatılmıştır. Bunun yanında diğer peygamberlerin giyim ve kuşamlarına değinilmiş, Hz. Süleyman'ın eşinin giyimi de anlatılmıştır.

"Sofra ve Yiyecekler" bahsinde Hz. Süleyman ve çevresindekilerin yediği yemekler, kullanılan yemek kapları, oturma düzeni vb. birçok halk unsuru göze çarpmaktadır. Yemekten sonra yapılan dualar, başkalarına yapılan ikramlar, insanları doyurma, yedirme, içirme vb. noktalara değinilmiştir. Yemek, tatlı ve şerbetlere dair eserde pek çok ayrıntı verilmiştir. Tatlıların günümüzde hala yenilen tatlılar olduğu göze çarpmaktadır.

Halk hekimliği ile ilgili olarak günümüzde de pek çok örneğini gördüğümüz halk hekimliği uygulamalarının eserin yazıldığı dönemde canlı bir şekilde yaşatıldı̆̆ı görülmektedir. Ayrıca eserde bazı bitkiler ve çeşitli karışımların birtakım hastlıklara iyi geldiği anlatılmaktadır.

Halk anlatılarımızda da yer alan sihir, efsun ve büyü ile ilgili malumatların verildiği bu eserde yazılı bir tılsım, metin halinde bulunmaktadır. Düğün, ölüm gibi geçiş dönemlerinde günümüzde de görülen el öpme, üç gün üç gece düğün yapılması gibi ritüeller görülmektedir.

Toplumlar sözel ve yazınsal eserlerle canlılığını sürdürür ve kendi kültürel çekirdeklerini oluşturdukları eserlerde ortaya koyarlar. Bu eserler de bir sonraki nesillere yine sözel ve yazınsal ürünlerle aktarılarak sonraki kuşağın mayasını oluştururlar. Toplumsal birlik beraberlik ve bireylerin 
toplumda belirli bir aidiyet kazanması için halka ait unsurların yazılması kadar onların derlenip ortaya çıkarılması da son derece önemlidir. Firdevsî-i Rûmî’nin Süleyman-nâme isimli eserinde 15. Yy’da yaşamış Türk toplumunun kültürel unsurlarına dair hala günümüzde de yaşanmaya devam eden pek çok geleneksel unsurlara rastlanılmıştır. Örneğin yemeklerden sonra yapılan duaların günümüzde de bir "ritüel gibi" yapılması toplumun geleceği ile geçmişinin arasındaki köprüyü göstermesi bakımından önemlidir. Günümüzde düğünlerin, özellikle son on yıla kadar, üç gün üç gece yapılması ve adet olarak tüm büyüklerin elinin öpülmesi geleneği 15. Yy’da yazılmış eserlerde de işlenmektedir. Eserde anlatılan hikâye ve mesellerde, her ne kadar Hz. Süleyman'ın hayatı konu alınmış ve tarihi tam olarak bilinmeyen bir zamandan bahsediliyor olsa da "her eser kendi döneminin çocuğudur" anlayışıyla yazarın yaşadığı dönemin kültürel unsurlarına yönelik pek çok örneğe rastlanılmaktadır. Bir milleti gerçek manada "millet" yapan unsurların başında makalede de işlendiği üzere kültürel unsurlar gelmektedir. Bu kültürel unsurlar, toplumların kaynaşması ve bir arada yaşama anlayışını geliştirmesi bakımından son derece önemlidir. Süleyman-nâme'nin de geçmişle gelecek arasında bir köprü kurması bakımından içerisinde pek çok halk anlayışını barındıran yazılı bir kaynak olması yönüyle önemli bir yeri vardır.

Eser oldukça hacimli bir eser olduğundan bu makalenin sınırları içerisinde böylesi hacimli çalışmanın sadece iki cildindeki metinlerin birkaç başlığı incelenebilmiştir. 80 cilt olduğu bilinen Süleyman-nâme'nin tüm ciltleri Latin harflerine aktarıldığında, bütüncül bir yaklaşımla tekrar ele alınıp kapsamlı bir şekilde değerlendirildiğinde geçmişle gelecek arasında "adet" "gelenek" ve "görenek" bakımından pek çok örneğe rastlamak mümkün olacaktır. Bu anlamda bu makale, Süleyman-nâme'deki halk kültürü üzerine bundan sonra yapılacak çalışmalara giriş mahiyetinde değerlendirilebilir. 


\section{KAYNAKÇA}

Aça, M. (2010). “Kaynaklar”, M. Öcal Oğuz (Ed.). Türk Halk Edebiyatı El Kitabı, s. 93- 128, İstanbul Grafiker Yayınları.

Ahmed, A, A. (2014). “Firdevsî-i Rûmî’nin Süleymannâme-i Kebîr-indeki Deyimler”, Turkish Studies Dergisi, Volume 9/9, Summer, p. 103-122.

Alangu, T. (1983). Türkiye Folkloru El Kitabl, İstanbul: Adam Yayınc1lık.

Alptekin, A, B. (2016). "Saltuknâme'nin Geçiş Dönemleri Açısından Değerlendirilmesi”, Millî Folklor Dergisi, Y11 2014, Say1 101.

Artun, E. (2007). Türk Halkbilimi, İstanbul: Kitabevi Yayınları. Babür, Y., Süleymân-nâme-i Kebir (6-7. Ciltler/İnceleme-Transkripsiyonlu Metin, Yayımlanmamış Yüksek Lisans Tezi, Erzincan Üniversitesi, Erzincan, 2013.

Bars, M. E. (2014). "Şor Kahramanlık Destanlarında Geçiş Dönemleri: Doğum-Evlenme-Ölüm” International Periodical For The Languages, Literature and History of Turkish or Turkic Volume 9/5 Spring 2014, p. 353-370,

Başgöz, İ. (1992). Sibirya'dan Bir Masal Anası, Ankara: Kültür Bakanlığı Yayınları.

Biçer, Bekir, Firdevsî-i Rumî ve Tarihçiliği, Yayımlanmamış Doktora Tezi, Selçuk Üniversitesi, Konya, 2005.

Boratav, P, N. (1997). 100 Soruda Türk Folkloru, İstanbul: Gerçek Yayınevi.

Diker, O. (2016). "Kültürel Miras ile Kültürel Miras Turizmi Kavramları Üzerine Kavramsal Bir Çalışma”, ASOS Journal, Akademik Sosyal Araştırmalar Dergisi, Yı1: 4, Sayı 30.

Ekici, M. (2004). "Halk Bilim Araştırmalarında Üçüncü Boyut”, Türklük Bilimi Araştırmaları Dergisi, Cilt 16, Sayı 16.

Erdem, Mehmet Dursun, Kitāb-ı Kıssanāme-i Süleymān Aleyhisselām Üzerine Söz Dizimi Çalışması (Süleymānnāme 74. cilt), Yayınlanmamış Doktora Tezi Ondokuz Mayıs Üniversitesi, Samsun, 2005.Firdevsî-i Rûmi, Süleyman-Nâme, 67 ve 68. Ciltler.

Gürçayır, S. (2011). “Somut Olmayan Kültürel Mirasın Korunması Sözleşmesi Üzerine Eleştirel Bir Okuma", Millî Folklor Dergisi, Y11 23, Say1 92.

Güvenç, B. (1974). Insan ve Kültür, İstanbul: Remzi Kitabevi.

Kaplan, M. (2012). Kültür ve Dil, İstanbul: Dergâh Yayınları.

Köprülü, O. F. (1996). “Firdevsî, Uzun”, İslam Ansiklopedisi, Cilt: 13, S: 127-129.

Ong, W, J. (2012). Sözlü ve Yazılı Kültür Sözün Teknolojileşmesi, İstanbul: Metis Yayınları.

Örnek, S, V. (2000). Türk Halkbilimi, Ankara: Kültür Bakanlığı Yayınları. 
Özcan, H. ve Gönenç C. S. (2015). "Yazılı ve Sözlü Kültür Ortamlarındaki Karaca Ahmet Sultan Menkabelerinin Karşılaştırılması”, International Periodical For The Languages, Literature and History of Turkish or Turkic Volume 10/4 Winter 2015, p. 717-746 DOI Number: http://dx.doi.org/10.7827/TurkishStudies.7710

Özdemir, C. (2011). Asşık Tarzı Türk Şiirinde Osmanlı Toplum Hayatı, İstanbul: Kitabevi Yayınları. Özünel, E. Ö. (2011). “Kültür Turizminde "Yöresel” ve “Otantik” Olanı Sorgulamak ve Tüketilmiş Mekânları Üretmek Üzerine", - International Periodical For The Languages, Literature and History of Turkish or Turkic Volume 6/4 Fall 2011, p.255-262

Sona, İ. (2016). "Yazılı Kaynaklarda, Kültürel Hafıza Cönkler”, Millî Folklor Dergisi, yı1 28, Sayı 111. 


\section{Summary}

Preserving culture and the idea of transferring, yet written works produced in the period in which the scientific basis is the source for folklore studies. These works, known as the cultural memory of Turkish literature, The period written contains information about the socio-cultural life. This information will be recorded in writing for cultural material in verbal memory and to learn the cultural life of that period and is valued the transfer points. The multifaceted nature of the cul- ture in terms of its features has led to its place in various fields in various literary works throughout history.

The development of written culture begins both to be written independently and to enter various written works in parts or sections. On this occasion researchers, they were able to follow the shapes of any known product from the previous centuries through these written sources. In fact, we can only be aware of the past existence of some folk literature products that have not reached the present in the oral culture environment through written works.

Of a rooted nation, the common values of a people's past, illuminating their beliefs; Even today, some of the cultural elements that maintain their operability, vitality and effectiveness and a lot of information that sheds light on the structures and roots of institutions, find the description in these source Works; networking connections between the present and the past, It is through written and verbal resources to save many cultural elements connected with the past from narrow patterns and connect them to their historical extension.

Firdevsî-i Rûmî, who gave his works in the Old Anatolian Turkish period, is a writer with many works of copyright and translation. In the books of Firdevsî who created many and many kinds of Works; with various information about his period, religious beliefs of human history, especially Eastern mythology, there is extensive information about prophet stories and various aspects of life.

Suleyman-nama is the most voluminous work in which all the religious and legendary stories told about Suleyman are gathered and that brought Long Firdevsi its fame.

Although there are many different narrations in the number of volumes and assemblies, a large volume of 81th remains to the present day. This work contains information about philosophy, knowledge and medicine. In this respect, it also has an encyclopedic work. Most of the work is prose. While verse sections are at the beginning and end, there are verse texts at the end of each story according to the subject. However, poetic parts make up very little of the work.

Suleyman-nama has a very important place in terms of the three sultans' years of reign, as well as the most voluminous work of its kind in Anatolia in terms of scope and content. Solomon-nama is very comprehensive in terms of the topics it contains, and besides addressing the stories and narrations formed around the Prophet Solomon, it also includes subjects of Eastern mythology, stories of other prophets, history, wisdom, philosophy, morality and medicine.

The work is written in a simple way, mixed in verse and prose, and draws attention to the harmony of voice and word repetitions in terms of harmony with Dede Korkut Stories.

In this study, which was carried out to determine the cultural codes and cultural elements carried from the 15 th century to the present as written sources, Among the folklore elements, the text obtained by translating the 67th and 68th volumes of Süleyman-nama into Latin letters was examined. Although the text in question appears at the first impression as the religious stories taking place around Suleiman's life, it actually shows an important written source feature for folklore researches. 
In the article which consists of introduction and conceptual framework and conclusion; Examples of socio-cultural life, folk medicine, beliefs and transition periods have been identified and each has been evaluated under separate headings. As can be seen, every example encountered in the work is shaped around the main hero, Süleyman. Süleyman's expression, clothing-dress, those around him, his table, etc. Many motifs of folk culture are encountered in the titles.

In this study, which has many elements from folk literature, it is focused on determining the data of folk culture in literary works.

Societies keep alive with verbal and literary works and present them in the works they create their own cultural core. These works are transferred to the next generations with verbal and literary products and form the yeast of the next generation. In order for social unity and individuals to gain a certain belonging in the society, it is very important to compile and reveal the elements of the public. In the work of Firdevsî-i Rûmî named Süleyman-nâme, many traditional elements that still continue to be lived today are encountered regarding the cultural elements of the Turkish society that lived in the 15th century. For example, making prayers after meals as a "ritual" is important in terms of showing the bridge between the future and past of the society. Today, the tradition of weddings, especially for the last decade, for three days and three nights, and the kissing of all elders in pieces is also covered in works written in the 15 th century.

In this article, as a method, text translation belongs to folklore and folk literature in the work named Süleyman-name, a number of elements related to the traditions, customs and lifestyles of the miletus have been identified and it has been concluded how these elements are used today. When all the volumes of Süleyman-nama, which is known to have 80 volumes, are transferred to Latin letters, when it is reconsidered with a holistic approach and evaluated comprehensively, It will be possible to come across many examples in terms of "custom", "tradition" and "custom" between the past and the future. In this sense, this article can be evaluated as an introduction to the future studies on folk culture in Süleyman-nama.

Keywords: Firdevsî-i Rûmî, Süleyman-nâme, Folklore, Written Memory, Culture. 